\title{
Hip osteoarthritis and dysplasia in Chinese men
}

\author{
E M C Lau, F Lin, D Lam, A Silman, P Croft
}

\begin{abstract}
Objective-To estimate the prevalence of hip osteoarthritis (OA hip) and hip dysplasia in a sample of Hong Kong men who were unselected with respect to hip symptoms.

Methods-The postmicturition films of 999 men aged 60-75 years, consecutive attenders for intravenous urography between 1987 and 1990 at a regional hospital, were reviewed. OA hip was diagnosed as the occurrence of two or more features of $O A$ using a modified version of the Kellgren and Lawrence scale, or a minimal joint space of $1.5 \mathrm{~mm}$ or less. Hip dysplasia was defined as a centre-edge angle of less than $25^{\circ}$, or an acetabular depth of less than $9 \mathrm{~mm}$. The results were compared with British data obtained by similar methods.
\end{abstract}

Results-In the Hong Kong sample, the proportion of men with two or more features of osteoarthritis in at least one hip was about $\mathbf{5 0} \%$ that of the men in the British study (5.4\% and $11.0 \%$, respectively). Severe joint space narrowing (of $1.5 \mathrm{~mm}$ or less) occurred in $0.7 \%$ of the hips in Hong Kong men, compared with $2 \%$ in the British men. The proportion of hips with centre-edge angles less than $25^{\circ}$ was $4 \cdot 5 \%$ in Hong Kong, compared with $3.6 \%$ in Britain, and the prevalence of shallow acetabular depth was greater in Chinese $(14 \cdot 5 \%)$ than in the British $(2 \cdot 1 \%)$. Radiographic measures of hip dysplasia were not associated with minimal joint space. Conclusions-Our results have confirmed the lower prevalence of radiographic hip osteoarthritis in Hong Kong men compared with British men. However, acetabular dysplasia was as prevalent among Chinese men as in the British sample. This is evidence against the hypothesis that variations in the frequency of hip osteoarthritis are caused by differences in the occurrence of hip dysplasia.

(Ann Rheum Dis 1995; 54: 965-969)

Osteoarthritis of the hip (OA hip) is an important cause of pain and disability, especially in the elderly, but its aetiology remains poorly understood. Its prevalence appears to vary widely between different populations, from an estimated $1-4 \%$ of adult black populations to $7-24 \%$ of white people. ${ }^{1}$ If the reasons for such geographical variation were identified, they would provide important clues to the aetiology of hip osteoarthritis.
One study that highlighted such geographical differences was a hospital based investigation carried out in Hong Kong two decades ago. ${ }^{2}$ This estimated that only $1 \%$ of Hong Kong Chinese men and women aged 55 years and over had radiographically detectable hip osteoarthritis. The authors hypothesised that the low prevalence of OA hip was attributable either to the rarity of developmental abnormalities such as hip dysplasia, or to the preventive effect of the squatting position popular among the Chinese.

It is difficult to compare prevalence estimates between studies from different countries because of contrasts in the selection of the study populations and in the definitions used for OA hip. We have therefore carried out a study to estimate the prevalence of hip osteoarthritris and hip dysplasia in a sample of Hong Kong men who were unselected with respect to hip symptoms, and to compare these estimates with results from a study carried out in 1987 in British men, ${ }^{3}$ which had used identical methods of sample selection and radiographic classification.

\section{Subjects and methods}

The study was carried out in a regional hospital in Hong Kong. From the radiograph register, we identified all 60-75 year old men who had attended for intravenous urograms during 1987-90. Their hip joints were then assessed from the control or postmicturition films. Radiographs were excluded if neither hip could be visualised adequately.

Features of radiographic osteoarthritis were assessed using two methods:

(i) A global qualitative score, modified from the Kellgren and Lawrence scheme, ${ }^{4}$ with a scale of $0-5$ based on a count of the number of features present. ${ }^{3}$ This assessment was made by the same observer as performed the task in the earlier British study (PC).

(ii) Ruler measurement of minimal joint space, defined as the shortest distance between the femoral head margin and the acetabulum. For purposes of this study, possible osteoarthritis of the hip was defined as a minimal joint space of $2.5 \mathrm{~mm}$ or less, and definite hip OA as a minimal joint space of $1.5 \mathrm{~mm}$ or less. ${ }^{3}$

The acetabular anatomy was assessed using two methods, illustrated in figure 1 . The centre-edge angle was defined as the angle formed by a line from the centre of the femoral head to the lateral margin of the acetabular roof and a line perpendicular to that joining the centres of the two femoral heads. The centres of the femoral heads were located with the aid of a transparent plastic sheet marked with concentric circles. If the femoral head was
Accepted for publication

18 August 1995 


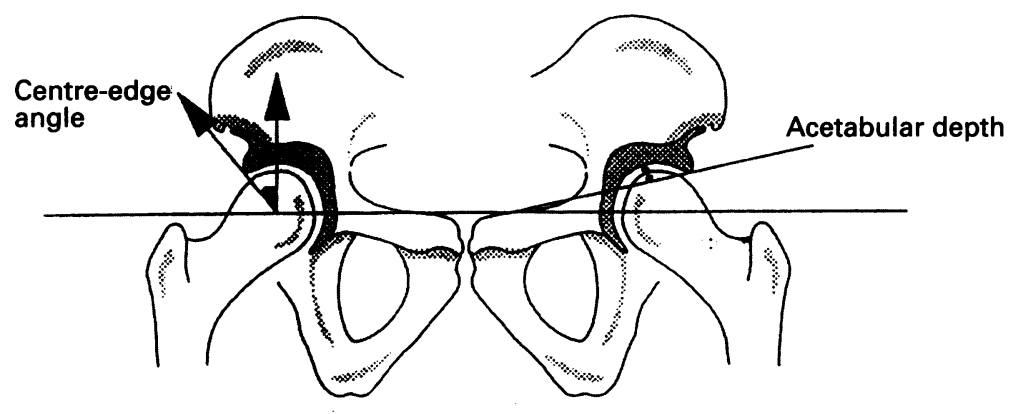

Figure 1 Measurements of acetabular dysplasia

deformed, the plastic sheet was aligned in relation to the unaffected areas. In identifying the lateral margin of the acetabular roof, we took account of any osteophytosis, and followed Wiberg's rule of identifying the lateral end of the dense acetabular 'eyebrow' on the radiograph. ${ }^{5}$ The acetabular depth was defined using Murray's method: the greatest perpendicular distance from the acetabular roof to a line joining the lateral acetabular margin to the symphysis pubis on the same side. ${ }^{6}$

In the presence of acetabular dysplasia the centre-edge angle and the acetabular depth are both small. Dysplasia was defined in two separate ways: a centre-edge angle of less than $25^{\circ}$, or an acetabular depth of less than $9 \mathrm{~mm} .^{6}$ Severe dysplasia was considered to be present if the centre-edge angle was $20^{\circ}$ or less.

The minimal joint space, centre-edge angle and acetabular depth were measured by one trained observer (FL). The results of these assessments were compared with results obtained from an earlier study of a sample of intravenous urograms in British men aged 60-75 years. This study had been carried out in 1987. The selection of films and methods of measurement were identical to those in the current study and were described in detail in an earlier publication. ${ }^{3}$

Repeatability was established both within and between observers using a subset of 40 Hong Kong hips. This subset was re-read after an interval of three months by the same observer (FL), and separately by the observer from the earlier British study (PC). In addition, a sample of the earlier British films were mixed with a sample of the Hong Kong films and re-read by the British observer (PC) in order to ensure that readings from the two studies were comparable.

ANALYSIS

The prevalence of osteoarthritis as defined by the overall grading was calculated by subject, a case being represented by involvement of one or both hips. All other analyses (minimal joint space, centre-edge angle, and acetabular depth) were by hip joint.

\section{Results}

Intravenous urograms showing the hip joints were available for 999 of the 1097 men identified from the radiograph register. None of the 1998 hips was found to have been replaced, or deformed by Paget's disease. Most views were adequate for the measurement of minimal joint space (1996 hips), centreedge angle (1993 hips) or acetabular depth (1991 hips). The mean age of the Hong Kong men was 70 (SD 7) years; the mean age of men in the earlier British study was 67 (SD 4) years.

PREVALENCE OF FEATURES OF OSTEOARTHRITIS Our results are presented alongside the data from the previous British study. Table 1 shows the distribution of overall qualitative grade. Isolated osteophytosis in at least one hip (grade 1) was as common in the Chinese as in the British men (14.8\% compared with $12.9 \%$, respectively). However, the proportion of men in the Hong Kong sample who had at least one hip showing two or more features of hip osteoarthritis (that is, grade 3 and above) was half that of the men in the British study $(5.4 \%$ and $11.0 \%$, respectively). There was a sixfold lower prevalence of osteoarthritis grade 4 and above among the Hong Kong men, representing an actual difference in prevalence between the two populations of $2 \cdot 2 \%$ (95\% confidence interval (CI) 1.3 to $3 \cdot 1 \%$ ).

Minimal joint space measurement was distributed unimodally in the hips of Hong Kong men, with a mean of $3.4 \mathrm{~mm}$, median $3.5 \mathrm{~mm}$, and SD $0.7 \mathrm{~mm}$. This was similar to the values obtained in Britain (mean $3.5 \mathrm{~mm}$ ). The prevalence of possible osteoarthritis based on minimal joint space was $13 \cdot 1 \%$ of all hips assessed in the Hong Kong sample (95\% CI 11.6 to $14.6 \%$ ); 14 hips had severe joint space narrowing ( $1.5 \mathrm{~mm}$ or less) - a prevalence for definite osteoarthritis of $0.7 \%(95 \%$ CI 0.3 to $1 \cdot 1 \%$ ) using this criterion. The corresponding figures in the British sample were $14.4 \%(95 \%$ CI 14.3 to $15.4 \%)$ and $2 \cdot 0 \%$ ( $95 \%$ CI 1.2 to $2.7 \%$ ), respectively, for possible and definite $O A$ based on minimal joint space.

PREVALENCE OF ACETABULAR DYSPLASIA

Centre-edge angle and acetabular depth were linearly related (correlation coefficient 0.75 ) (fig 2). Table 2 summarises their distribution

Table 1 Prevalence of radiographic osteoarthritis in at least one hip among 999 Chinese men (1987-90) and 1315 English men (1982-87) aged 60-75 years: overall qualitative assessment

\begin{tabular}{|c|c|c|}
\hline Grade* & $\begin{array}{l}\text { Chinese men } \\
(n=999) \\
(\%)\end{array}$ & $\begin{array}{l}\text { British ment } \\
(n=1315) \\
(\%)\end{array}$ \\
\hline $\begin{array}{l}4 \\
5\end{array}$ & $\begin{array}{r}69.5 \\
14.8 \\
10 \cdot 2 \\
5.0 \\
0.3 \\
0.1\end{array}$ & $\begin{array}{r}62.8 \\
12.9 \\
13.3 \\
8.4 \\
1.5 \\
1.1\end{array}$ \\
\hline \multicolumn{3}{|c|}{$\begin{array}{l}\text { ^Criteria for overall qualitative assessment of OA hip: } \\
0=\text { No osteoarthritic changes } \\
1 \text { = Osteophytosis only } \\
2 \text { = Joint space narrowing only } \\
3 \text { = Two of: osteophytosis, joint space narrowing, subchondral } \\
\text { sclerosis, cyst formation } \\
4 \text { = Three of: osteophytosis, joint space narrowing, subchondral } \\
\text { sclerosis, cyst formation } \\
\text { 5 = As in grade 4, but with deformity of fëmoral head } \\
\text { †British figures from reference } 3 \text {. }\end{array}$} \\
\hline
\end{tabular}




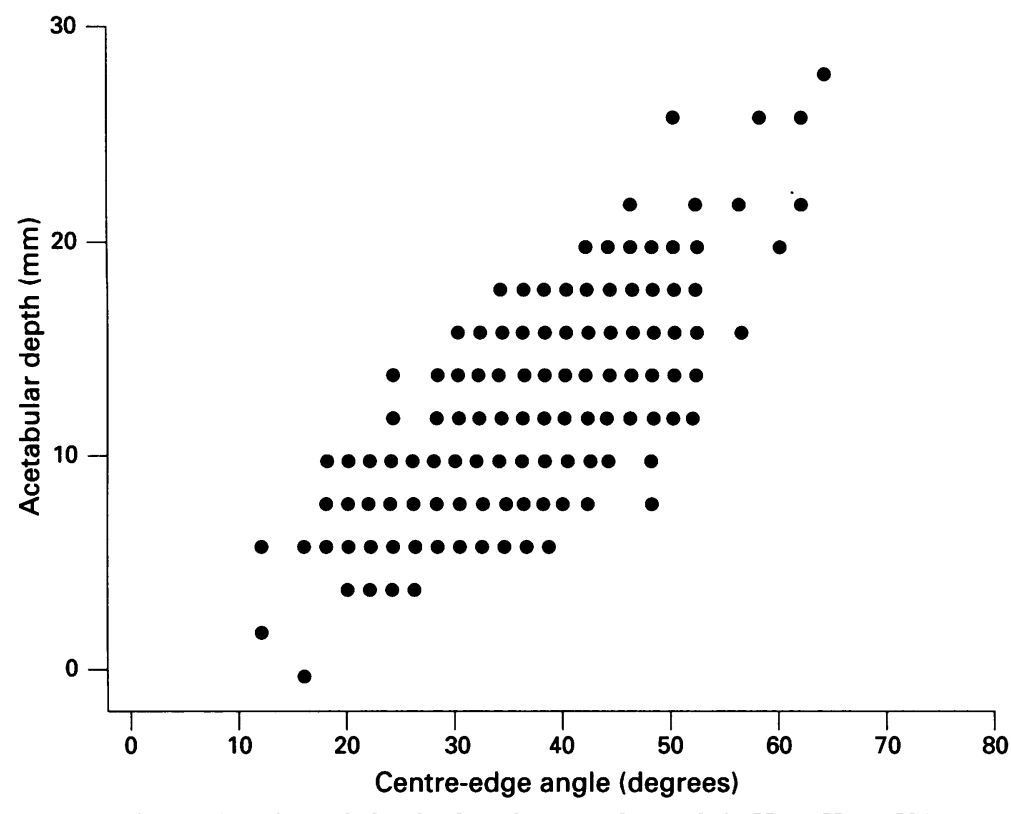

Figure 2 Association of acetabular depth and centre-edge angle in Hong Kong Chinese $(\mathrm{r}=0.75)$
Table 3 Association between measures of acetabular anatomy and minimal joint space in Hong Kong Chinese men

\begin{tabular}{lcc}
\hline & \multicolumn{2}{c}{ Minimal joint space (hips) } \\
\cline { 2 - 3 } & $\geqslant 4.0 \mathrm{~mm}$ & $\leqslant 1.5 \mathrm{~mm}$ \\
\hline Centre-edge angle & & \\
Number of hips & 666 & 12 \\
Mean (deg) & 33.6 & 38.6 \\
Median (deg) & 33.0 & 39.0 \\
SD (deg) & $6 \cdot 3$ & 6.6 \\
$<25^{\circ}(\%)$ & $48(7 \cdot 2)$ & $0(0)$ \\
$\leqslant 20^{\circ}(\%)$ & $10(1.5)$ & $0(0)$ \\
Acetabular depth & & \\
Number of hips & 666 & 13 \\
Mean (mm) & 11.5 & 13.5 \\
Median (mm) & 11.5 & 14.0 \\
SD (mm) & 3.1 & 3.9 \\
$<9$ mm (\%) & $120(18)$ & $1(7 \cdot 7)$ \\
\hline
\end{tabular}

minimal joint space in Hong Kong men. The prevalence of dysplasia in the 14 hips with a minimal joint space of $1.5 \mathrm{~mm}$ or less was compared with that in the 667 hips with a minimal joint space of $4.0 \mathrm{~mm}$ or more (the upper third of the distribution of minimal joint space in the Hong Kong sample). There was little difference in the prevalence of dysplasia, whether measured by centre-edge angle or by acetabular depth, between hips with and without a narrowed joint space. This lack of a relationship was also reported in the study of British men. ${ }^{7}$ in the British sample $\left(36.2^{\circ}\right)$, and the prevalence of small angles (and by implication the prevalence of acetabular dysplasia) was similar in the two populations. The proportion of hips with angles of less than $25^{\circ}$ was $4.5 \%$ in Hong Kong (95\% CI 3.6 to $5.4 \%$ ), compared with $3.6 \%$ in Britain (95\% CI 3.4 to $3.8 \%$ ); severe dysplasia (angles of $20^{\circ}$ or less) affected $1.1 \%$ (95\% CI 1.09 to $1.2 \%$ ) of hips in Hong Kong, compared with $1.0 \%$ in Britain (95\% CI 0.3 to $1 \cdot 7 \%$ )

Dysplasia based on the measurement of acetabular depth presented a rather different picture. The mean depth in the Chinese men was less than the mean in the British sample (difference in means $-2.6 \mathrm{~mm}, 95 \% \mathrm{CI}-2.4$ to $-2.8 \mathrm{~mm}$ ), and the prevalence of shallow acetabula with a depth less than $9 \mathrm{~mm}$ was consequently greater in the Chinese (difference in prevalence $12 \cdot 4 \%, 95 \%$ CI 9.9 to $14.9 \%$ ).

RELATIONSHIP BETWEEN OSTEOARTHRITIS AND DYSPLASIA

Table 3 shows the relationship between the measures of acetabular dysplasia and the

Table 2 Distribution of centre-edge angle and acetabular depth in Hong Kong Chinese men compared with British men

\begin{tabular}{lcc}
\hline & Chinese men & British ment \\
\hline Centre-edge angle & & \\
Number of hips & 1993 & 2604 \\
Mean (deg) & 35.5 & $36 \cdot 2$ \\
Median (deg) & 35.0 & $36 \cdot 0$ \\
SD (deg) & $6 \cdot 6$ & $6 \cdot 9$ \\
$<25^{\circ}(\%)$ & $89(4 \cdot 5)$ & $94(3 \cdot 6)$ \\
$\leqslant 20^{\circ}(\%)$ & $21(1 \cdot 1)$ & $26(1 \cdot 0)$ \\
Acetabular depth & & \\
Number of hips & 1991 & 2557 \\
Mean (mm) & $11 \cdot 8$ & $14 \cdot 4$ \\
Median (mm) & 11.5 & $14 \cdot 0$ \\
SD (mm) & 3.0 & 3.1 \\
$<9$ mm (\%) & $289(14 \cdot 5)$ & $54(2 \cdot 1)$ \\
\hline
\end{tabular}

†British figures from reference 7 .

\section{REPEATABILITY}

In the sample of Hong Kong films used to examine repeatability, the means of the differences between the observers were $1.6^{\circ}$ for centre-edge angle, $0.1 \mathrm{~mm}$ for acetabular depth, and $0.2 \mathrm{~mm}$ for minimal joint space. Such values indicate that there was little systematic error between observers. The within observer error in categorising films to grades 3-5, according to the modified Kellgren and Lawrence score, was similar to that observed in the original British study, unaffected by the presence of Hong Kong films in the mixed repeatability sample.

\section{Discussion} graphic osteoarthritis in the hips of a sample of Hong Kong Chinese men aged 60 to 75 years to be $0 \cdot 7 \%$ based on joint space measurement alone. The proportion of men with at least one hip showing three or more radiographic features of osteoarthritis was $0.5 \%$. These frequencies were lower than those found in British men of the same age, selected and assessed in the same way. The study population was selected on the basis of gender, age, and presentation for an intravenous urogram. Our conclusions cannot be taken to represent osteoarthritis in younger adults or in women. However, it is likely that this age group is representative of older Hong Kong men in general, and these are the ages when hip osteoarthritis is most common.
We have found the prevalence of definite radio-

WEAKNESSES AND STRENGTHS OF THIS STUDY 
Dysplasia appears to be a more important influence on hip osteoarthritis presenting in young adults, ${ }^{8}$ but such patients form only a minority of all presenting cases of OA hip in Britain, and there is no evidence to suggest that this problem is common in young Hong Kong Chinese.

Most intravenous urograms in Hong Kong men older than 60 years are performed to investigate prostatism, and there is no reason to suppose that such men are unrepresentative of other men of this age in the general population with respect to hip symptoms and osteoarthritis.

A strength of the comparison with the British study is the identical methodology. Radiographic definitions of osteoarthritis are always arbitrary, but there is evidence to support the use of minimal joint space as the main criterion in large surveys. ${ }^{3}$ We did not study symptoms in the Hong Kong sample, and it is possible that symptoms and radiographs have a relationship different than that observed in Britain. However, this would not have affected the radiographic comparison that was the main focus of this study.

COMPARISON WITH OTHER STUDIES: HIP OA A direct comparison with an earlier British study $^{3}$ was possible because the age of the subjects, their method of selection, and the method of assessment were identical between the two studies. The mean minimal joint space and the prevalence of isolated osteophytosis were similar in the two populations, but the prevalence of osteoarthritis was lower in the Hong Kong men compared with the British men.

A second comparison may be made with the earlier study of Hoaglund et al. ${ }^{2}$ They investigated 500 Hong Kong Chinese by identifying every fifth patient admitted to any service of a single hospital, including a minority who were attending as outpatients. Pelvic radiographs were then obtained of all patients. This study had the advantage that radiographs were taken specifically for purpose of the study, but the disadvantages that the population was highly selected (mostly confined to hospital) and the numbers in each age and sex grouping were relatively small. No direct comparison is possible with our study because of the different methods of radiographic assessment. The estimated prevalence of severe osteoarthritis in men aged 65-74 years in the study by Hoaglund's group was $2 \cdot 7 \%$, rather less than the estimate based on global assessment of the presence of two or more radiographic features in our study. Nevertheless, the broad conclusion that the prevalence of hip osteoarthritis is lower in the Hong Kong Chinese than in British men of the same age is supported by both Hong Kong studies, despite their different methodologies.

A study of 99 men from a rural population sample in Japan found no cases of hip osteoarthritis, defined as two or more radiographic features and using a method of qualitative grading identical to that described here. ${ }^{9}$
COMPARISON WITH OTHER STUDIES:

ACETABULAR ANATOMY

An association between $O A$ hip and hip dysplasia has been described from radiological observations in patients admitted to hospital with OA hip ${ }^{6810}$ and from follow up studies of subjects with dysplastic hips. ${ }^{11}$ However, the absence of a link between measures of acetabular dysplasia and joint space narrowing in our study of Hong Kong males attending for urography is similar to the finding from the parallel British study. ${ }^{7}$ In addition, the prevalence of dysplasia as measured by the centre-edge angle was remarkably similar in the two studies.

The centre-edge angle measurements were also consistent with those reported in other studies. In the 74 men aged $60-74$ years from Hoaglund's sample of Hong Kong Chinese, ${ }^{2}$ the mean centre-edge angle was $36^{\circ}\left(\mathrm{SD} 5^{\circ}\right.$ ). This is very close to the figures from both the current study and the British sample. The prevalence of angles less than $25^{\circ}$ was $5 \%$, again similar to that in the present study. The main reason for Murray's recommendation to use acetabular depth ${ }^{6}$ was the possibility that centre-edge angle measurements could be affected by osteophytosis and migration of the femoral head. However, the consistency of results for centre-edge angle across time and place in these three studies would lead us to conclude that there is no firm evidence that the prevalence of acetabular dysplasia is different in Hong Kong men compared with British men, and that the difference in the prevalence of hip OA in the two populations cannot be explained by corresponding differences in the occurrence of acetabular dysplasia. Indeed, evidence from Japan suggests that populations geographically closer to Hong Kong may actually have a higher prevalence of dysplasia, as measured by the centre-edge angle, ${ }^{9}$ despite a comparably low prevalence of hip osteoarthritis.

In contrast, when the acetabular depth measurements were compared, acetabula in the Hong Kong Chinese sample were shallower than in British men. This might be an artefact of the positioning of the $x$ ray tube relative to the hips; alternatively, acetabular configuration may be different in Chinese men. In the British intravenous urogram study, the data suggested that the relationship between acetabular depth and hip osteoarthritis was actually opposite to that hypothesised-that is, radiographic joint space narrowing was associated with a deep acetabulum. Such an acetabular shape may arise from developmental hip diseases other than dysplasia-slipped capital femoral epiphysis, for example. The twin observations of a smaller mean acetabular depth and a lesser prevalence of hip osteoarthritis in Chinese men raises the possibility that shallow acetabula may actually protect the hips from osteoarthritic changes later in life, perhaps because of altered mechanical loading.

Our study cannot address whether other variations in acetabular anatomy might be linked to the different rates of hip osteoarthritis and whether the same lack of an association 
between osteoarthritis and centre-edge angles would be found in Chinese women living in Hong Kong.

\section{Conclusions}

Our results confirm the lower prevalence of radiographic hip osteoarthritis in Hong Kong men compared with British men. The study has provided no evidence of a lower prevalence of adult acetabular dysplasia among the Hong Kong Chinese men compared with British men, and this argues against the hypothesis that geographical variations in the frequency of hip osteoarthritis are caused by differences in the occurrence of dysplasia.

It is possible that variations in the frequency of other conditions might explain the differences in the prevalence of hip OA. Rheumatoid arthritis is rare in Hong Kong compared with white populations, ${ }^{12}$ although clinical rheumatoid arthritis explains only a very small proportion of cases of hip OA in the West. Anecdotal evidence suggests that slipped capital femoral epiphysis and Perthes disease are rare in the Chinese, and this might have a small influence on the prevalence of OA hip. Other host and lifestyle factors may contribute to the rarity of hip osteoarthritis in the Hong Kong Chinese. There is variable evidence for a link between obesity and radiographic hip osteoarthritis, although most studies suggest an association. ${ }^{13}$ Obesity is much rarer in Chinese than in white populations, ${ }^{14}$ and this may partly account for the lower prevalence of hip osteoarthritis among the Hong Kong men in our study.

A major risk for hip osteoarthritis in Europe is physical activity which places stress on the lower limbs: the excess of hip osteoarthritis in European farmers might be explained in this way..$^{15}$ It is difficult to suppose that the Chinese place any less stress on their hips, although it has been suggested that the squatting posture popular in former times (when this cohort of men were young adults) protected the hip cartilage against damage. ${ }^{16}$ The possibility that some aspect of the lifestyle in the Chinese culture is protective of the hip remains an attractive one, whilst the influence of genetic differences on geographic variations in the occurrence of osteoarthritis remains to be explored.

This work was supported by a project grant from The Arthritis and Rheumatism Council of Great Britain.

The methodology for the study was developed at the Medical Research Council's Environmental Epidemiology Unit in Southampton by Drs David Coggon and Cyrus Cooper, who

1 Lawrence J S, Sebo M. The geography of osteoarthritis. In: Nuki G ed The aetiopathogenesis of osteoarthrosis. In: Nuki G, ed. The aetiopathogenesis of osteo

2 Hoaglund F T, Yau A C M C, Wong W L. Osteoarthritis of the hip and other joints in Southern Chinese in Hong Kong. F Bone foint Surg Am 1973; 55: 545-57.

3 Croft P, Cooper C, Wickham C, Coggon D. Defining osteoarthritis of the hip for epidemiologic studies. Am $\mathcal{F}$ Epidemiol 1990; 132: 514-22.

4 Kellgren J H, Lawrence J S. Radiological assessment of osteoarthrosis. Ann Rheum Dis 1957; 16: 494-502.

5 Wiberg G. Studies on dysplastic acetabula and congenital subluxation of the hip joint. Acta Chir Scand 1939; 58 (suppl): $1-135$.

6 Murray R O. The aetiology of primary osteoarthritis of the hip. Br F Radiol 1965; 38: 810-24.

7 Croft P, Cooper C, Wickham C, Coggon D. Osteoarthritis of the hip and acetabular dysplasia. Ann Rheum Dis 1991; 50: 308-10.

8 Stulberg $S$ D, Harris $W H$. Acetabular dysplasia and development of osteoarthritis of the hip. In: Harris W H, ed. The hip. Proceedings of the second open scientific meeting of the Hip Society. St Louis: Mosby, 1974; 82-93.

9 Yoshimura N, Campbell L, Cooper C, et al. Acetabular dysplasia in Britain and Japan. Br $\mathcal{F}$ Rheumatol 1994; 33 (suppl 1): 102

10 Solomon L. Patterns of osteoarthritis of the hip. F Bone foint Surg Br 1976; 58: 176-83.

11 Cooperman D R, Wallenstein R, Stulberg S D. Acetabular dysplasia in the adult. Clin Orthop 1983; 175: 79.

12 Lau E, Symmons D, Bankhead C, Macgregor A, Donnan S, Silman A. Low prevalence of rheumatoid arthritis in the urbanized Chinese of Hong Kong. $¥$ Rheumatol 1993; 20: urbanized

13 Vingard E. Overweight predisposes to coxarthrosis. Acta Orthop Scand 1991;62: 106-9.

14 Ho S C. Risk factors for obesity among Hong Kong youths. Public Health 1990; 104: 249-55.

15 Croft P, Coggon D, Cruddas, Cooper C. Osteoarthritis of the hip: an occupational disease in farmers. BMF 1992; 304: 1269-72.

16 Gunn D R. Don't sit-squat! Clin Orthop 1974; 103: $104-5$ 